\title{
An Accurate Determination of Induction Machine Equivalent Circuit Components
}

\author{
$1^{\text {st }}$ Bilal Abdullah Nasir ${ }^{1}$ \\ \{email : bilal_alnasir1958@yahoo.co.uk ${ }^{1}$ \} \\ Northern Technical University, Hawijah Technical Institute, Iraq.
}

\begin{abstract}
This paper is to propose a procedure for the determination of complete components of the induction machine equivalent circuit at various operating conditions, considering the effect of skin and temperature on the stator winding, rotor winding, and iron core losses calculations. Also, the variation of temperature on speed (slip), the variation of speed on mechanical (friction and windage) losses, magnetizing saturation effect, slip effect on the iron core losses and skew effect on the machine parameters are considered.

Besides these parameters effect, the method of equivalent circuit parameters determination requires measurements of supply voltage per phase, stator current per phase from no-load to full-load points, stator D.C. resistance per phase at ambient temperature, no-load test at different supply voltages from $125 \%$ down to $25 \%$ and a locked-rotor test at a variable frequency from $100 \%$ down to $10 \%$ of rated. In this method, the air-gap magnetizing voltage, the machine power factor, the stator iron core resistance, the rotor iron core resistance, the stator stray loss resistance, and rotor stray loss resistance are accurately determined to achieve excellent accuracy using this proposed methodology.
\end{abstract}

Keywords: Induction machines; Equivalent circuit; Iron core loss; stray load loss; friction and windage loss; skew factor; temperature factor;

\section{1-Introduction}

In fact, stator parameters are changed with skin-effect and winding temperature, rotor parameters are changed with slip and bars temperature, iron core resistances for stator and rotor are changed with slip (especially rotor core resistance) and core temperature, the stray loss resistance is changed with slip and core temperature and the mechanical loss resistance is changed with motor speed and magnetic saturation [1-7].

Hence, an accurate estimation of machine equivalent circuit parameters is required to implement these parameters in a high-performance determination. The stator and rotor winding temperatures can be determined according to the IEEE standard 112-B by measuring the stator no-load and load currents, and the rotor current can be determined at different load conditions. The skin effect on the stator parameters can be determined from the stator geometry. The skineffect in the rotor parameters can be calculated by using a formula given in [3]. The iron core resistances can be determined from the no-load test considering the effect of slip and core temperature. The magnetizing reactance can be calculated from the no-load test at different supply voltage and at the rated frequency to consider the saturation effect.

In the following sections, the per-phase equivalent circuit of the induction machine, the power flow diagram and parameters calculation procedure are presented for accurate determination of machine parameters from a modified equivalent circuit. 


\section{2- Equivalent Circuit of Induction Machine}

The conventional equivalent circuit of induction machine has usually been modeled by means of per-phase quantities, with the magnetizing branch consists of constant iron core resistance $\left(R_{i c}\right)$ in parallel with the constant magnetizing reactance $\left(X_{m}\right)$, both in ohms, as shown in figure (1). The stator and rotor resistances and leakage reactance are $R_{s}, R_{r}, X_{\ell s}$ and $\dot{X}_{\ell r}$ respectively. These parameters are assumed to be constant, and this equivalent circuit can be used only for machine performance calculations with constant machine parameters. The modified equivalent circuit is shown in figure (2). In this circuit, the effect of motor slip on the iron core losses, the effect of stray loss in the stator and rotor circuit, the effect of mechanical loss, and the effect of magnetic saturation on the motor performance can be considered.

The stator and rotor resistances $R_{s}$ and $R_{r}$ are depending on the temperature variation and skin-effect. The stator and rotor leakage reactance's $X_{\ell s}$ and $\dot{X}_{\ell r}$ are depended on skin-effect and saturation. The magnetizing inductance $X_{m}$ depends on the magnetic saturation. The iron core resistance, which is added for stator and rotor iron cores, $\left(R_{i c}\right)$ depends on motor slip and iron core temperature. The modified equivalent circuit contains additional resistances $R_{\text {sss }}$ and $R_{\text {rsse }}$ that model the stray losses in the stator and rotor circuits. These stray losses depended on the voltage drops due to the leakage reactance, the iron core resistances, and stator, and rotor resistance. Also, the modified equivalent circuit contains a particular resistance $R_{f \omega}$ to deal with the mechanical losses due to these losses are a function of machine speed, magnetic saturation, and air-gap magnetizing voltage.

The equivalent circuit of a figure (2) can be modified as the proposed equivalent to including the effect of rotor skewing on the parameters of the rotor circuit, as shown in figure (3).

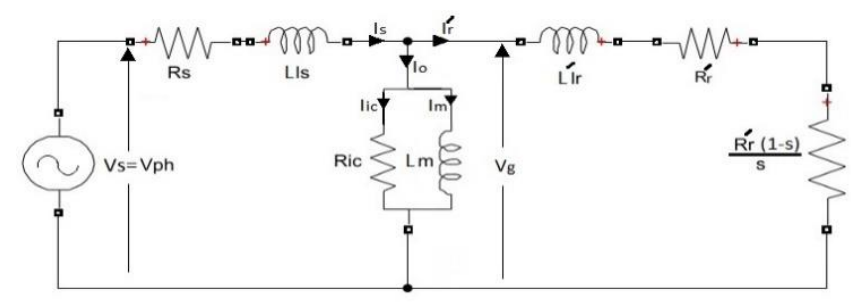

Fig. 1. Conventional equivalent circuit of induction machine per phase

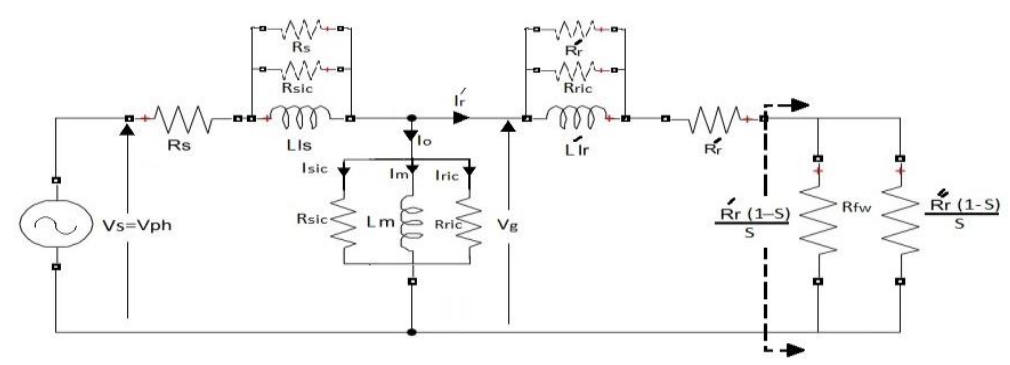

Fig. 2. Modified induction machine equivalent circuit per phase, including iron core losses, stray load losses, and mechanical losses. 


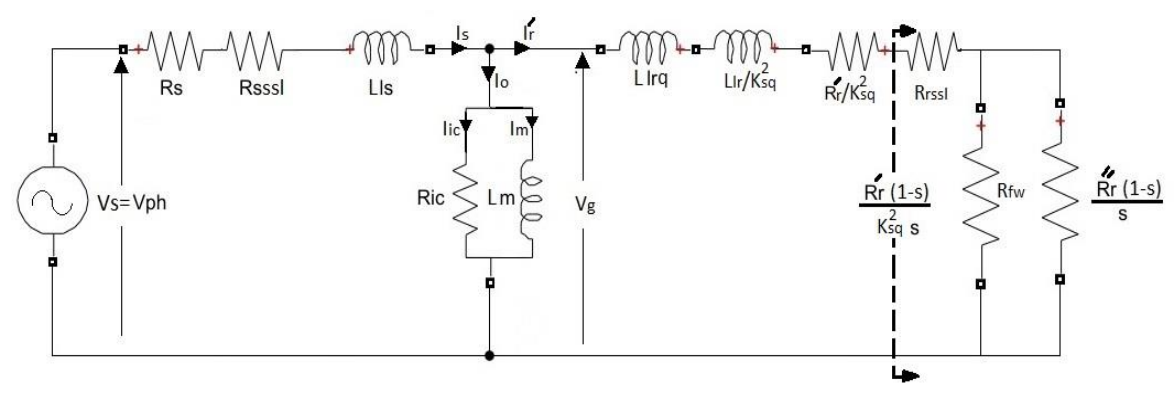

a-) Proposed equivalent circuit for motor

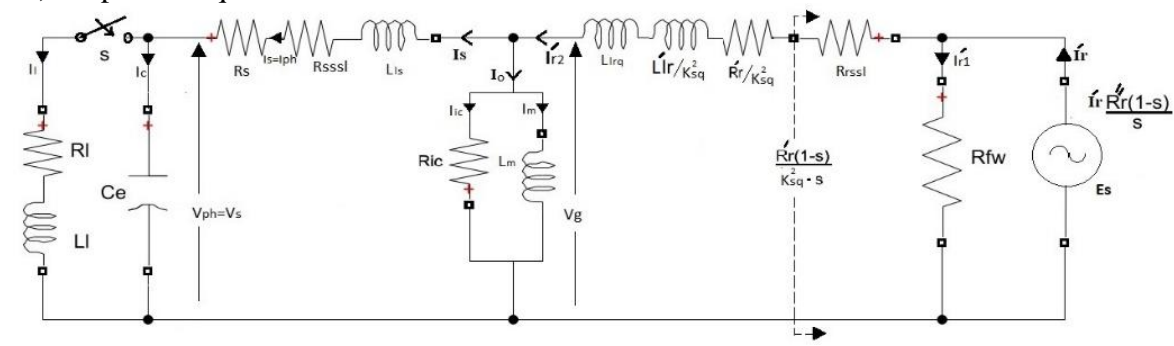

b-) Proposed equivalent circuit for generator

Fig. 3. The proposed equivalent circuit of the induction machine considering the skew effect, stray load loss, iron core loss, and mechanical losses.

\section{3- Induction Machine Power -Flow Diagram According to Modified Equivalent Circuit}

The power -flow diagram in figure (4) shows the relation between the electric input power $\left(P_{i n}\right)$, the air-gap power $\left(P_{a g}\right)$, the mechanical output power $\left(P_{m}\right)$ and the shaft or net output power $\left(P_{\text {sh }}\right.$ or $\left.P_{\text {out }}\right)$. The difference between $P_{\text {in }}$ and $P_{\text {out }}$ is known as the total power losses. All the power loss components are described as follow:

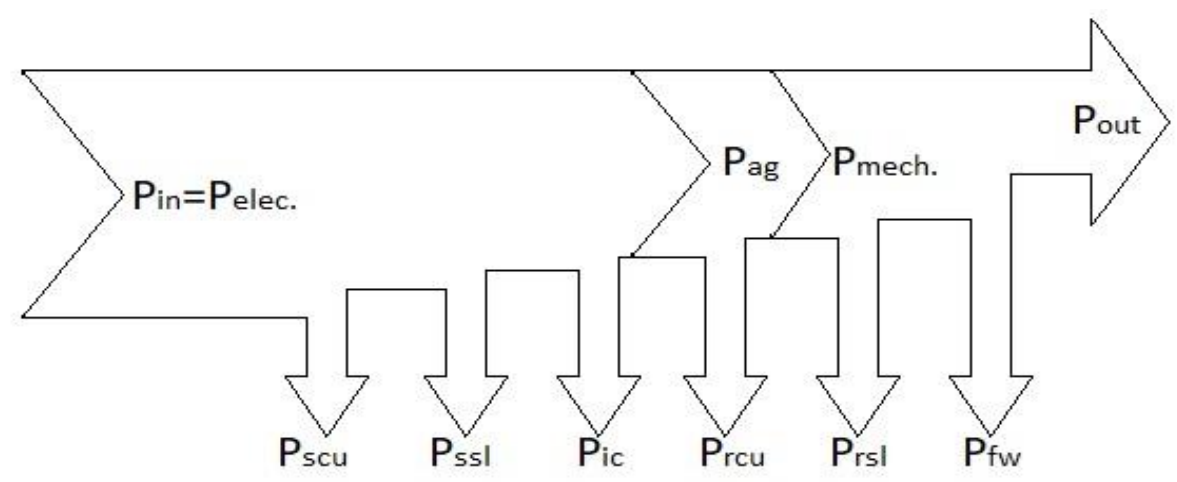


a-) Power flow of induction motor.

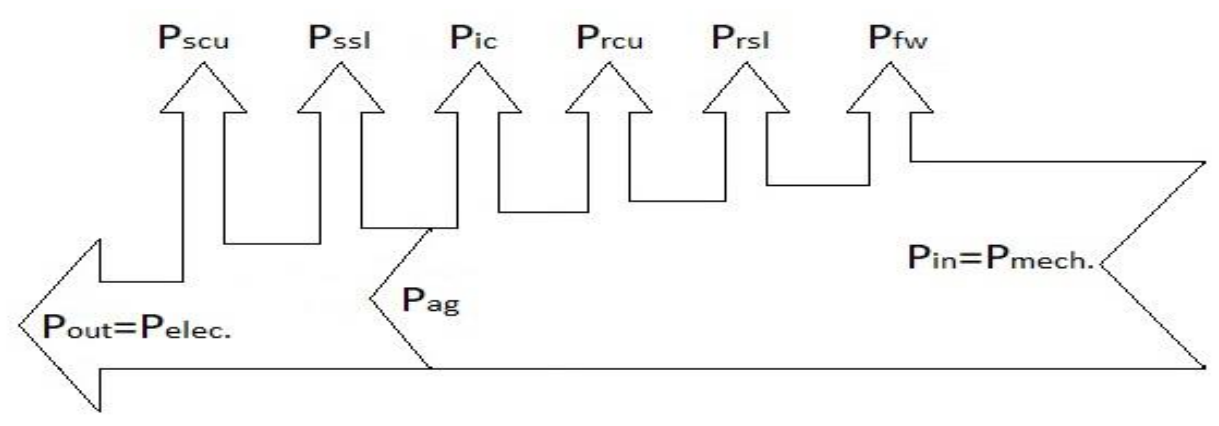

b-) Power flow of induction generator.

Fig. 4. Power flow diagram according to the modified equivalent circuit of the induction machine.

$P_{s c u}$ is the stator winding copper loss, which depends on the stator current $\left(I_{S}\right)$ and stator winding resistance $\left(R_{S}\right)$ and can be calculated as :

$$
P_{s c u}=3 * I_{s}^{2} * R_{s}
$$

$P_{\text {ssS }}$ is the stator series stray loss, which is represented by a resistance $\left(R_{\text {sss }}\right)$ connected in series with the stator circuit, and this loss can be calculated as :

$$
P_{s s l}=3 * I_{s}^{2} * R_{s s S \ell}
$$

$P_{i c}$ is the total iron core losses and can be calculated as :

$$
P_{i c}=3 * I_{i c}^{2} * R_{i c}=3 * V_{g}^{2} / R_{i c}
$$

where $V_{g} \quad=$ the magnetizing voltage of the air-gap per-phase.

$P_{r c u}$ is the rotor winding (bars) copper loss and depends on the rotor current $\left(I_{r}\right)$ and rotor resistance $\left(R_{r}\right)$ and can be calculated as :

$$
P_{r c u}=3 * I_{r}^{2} * \dot{R}_{r}
$$

$P_{\text {rss }}$ is the rotor series stray loss, which is represented by a resistance $\left(R_{r s s \ell}\right)$ connected in series with rotor circuit, and this power loss can be calculated as:

$$
P_{r s s \ell}=3 * I_{r}^{2} * R_{r s s \ell}
$$

$P_{f \omega}$ are the friction and windage (mechanical) losses and depends on the air-gap magnetizing voltage and the friction and windage losses resistance $\left(R_{f \omega}\right)$. This power loss can be calculated as:

$$
P_{f \omega}=3 *\left[V_{g}-I_{r} *\left(R_{s}+R_{r s s \ell}+j \dot{X}_{r}\right)\right]^{2} / R_{f \omega}
$$


$\approx 3 * V_{g}^{2} / R_{f \omega}$

Where $\dot{X}_{r}$ is the rotor leakage reactance referred to stator plus the leakage reactance due to the rotor skew-effect as:

$X_{r}^{\prime \prime}=\dot{X}_{\ell r}+X_{\ell r q}$

$$
X_{\ell r q}=X_{m} \cdot\left(\frac{1}{K_{s q}^{2}}-1\right)
$$

\section{4- Parameters Calculation of Modified and Proposed Equivalent Circuits}

This paper aims to develop a novel and accurate methodology for calculation of the equivalent circuit parameters of the induction machine from DC resistance test, no-load test, temperature test, locked rotor test, and its name-plate and the manufacture data-sheet. The name-plate of the machine contains information about the rated quantities such as shaft power, voltage, current, power factor, speed, and efficiency. The manufacturing datasheet contains the slip at maximum torque, rated slip, the design class, and insulation class for determination of leakage reactances and machine rated temperature. The following procedure shows how the machine parameters can be determined as variable parameters.

The stator and rotor resistances and leakage reactances are varying with temperature and skin effect. The iron resistances are varying with temperature and slip. The lost resistances of stray are varying with the temperature. Also, the mechanical loss resistance is varying with speed and magnetizing saturation, and the skew effect can be considered as a factor affecting the rotor circuit parameters.

A- DC resistance test: From this test, the stator resistance per phase can be calculated for star connection stator windings as:

$$
R_{S(o)}=V_{\text {d.c. }} /\left(2 * I_{d c}\right)
$$

Where $R_{S(o)} \quad=$ the stator resistance at ambient temperature.

B- Locked-Rotor test: From this test the rotor circuit parameters $\dot{R}_{r}$ and $\dot{X}_{\ell r}$ as well as stator leakage reactance can be determined at rated current and low voltage as:

$$
\begin{gathered}
Z_{s c}=V_{s c} / I_{s c} \\
R_{s(o)}+\dot{R}_{r(o)}=Z_{s c} * \cos \left(\phi_{s c}\right) \\
\dot{R}_{r(o)}=Z_{s c} * \cos \left(\phi_{s c}\right)-R_{s(o)} \\
X_{\ell s(o)}+\dot{X}_{\ell r(o)}=\sqrt{Z_{s c}^{2}-\left(R_{s(o)}+\dot{R}_{r(o)}\right)^{2}}
\end{gathered}
$$

And according to the design class the stator and rotor leakage reactance $\left(X_{\ell s(o)}\right.$ and $\left.\dot{X}_{\ell r(o)}\right)$ can be separated.

C- No-load test: In this measurement, the tested machine is rotated at synchronous speed by another coupled motor such as DC motor without load at rated voltage and frequency to separate the friction and windage losses from the other no-load losses (iron core and stator 
copper losses), and to obtain Zero slip at no-load for determination stator and rotor core resistances $R_{\text {sic }} \& R_{\text {ric }}$. Then, the machines are operated at no load with variable supply voltage, in steps, ranging from $125 \%$ to $25 \%$ of rated voltage to determine the magnetizing characteristics (magnetizing inductance as a function of no-load current) and to find the relation between motor speed and magnetizing voltage for calculation of mechanical loss resistance $\left(R_{f \omega}\right)$. Also, from this test the stator and rotor stray loss resistances $R_{s s s \ell}$ and $R_{r s s \ell}$ can be determined. These parameters can be determined per phase as follow:

The no-load power per phase $\left(P_{n \ell}\right)$ is given as:

$$
\begin{gathered}
P_{n \ell}=V_{p h} * I_{o} * \cos \left(\phi_{n}\right) \\
\sin \left(\phi_{o}\right)=\sin \left(\cos ^{-1}\left(\phi_{o}\right)\right)
\end{gathered}
$$

The reactive power per phase at no-load can be determined as:

$$
Q_{n \ell}=V_{p h} * I_{o} * \sin \left(\phi_{o}\right)
$$

The magnetizing (air-gap) voltage per phase can be calculated as [8]:

$$
V_{g}=\sqrt{\left[V_{p h}-\frac{\left(R_{S} \cdot P_{n \ell}+X_{\ell S} \cdot Q_{n \ell}\right.}{V_{p h}}\right]^{2}+\left[\frac{\left(X_{\ell s} \cdot P_{n \ell}-R_{S} \cdot Q_{n \ell}\right)}{V_{p h}}\right]^{2}}
$$

The stator iron core resistance $R_{\text {sic }}$ per phase can be determined as :

$$
R_{\text {sic }}=V_{g}^{2} /\left[K_{T} *\left(P_{n \ell}-I^{2} \cdot R_{s}\right)\right]
$$

Figure (5) shows the variation of iron core resistance with air-gap magnetizing voltage from the no-load test when the machine rotates at synchronous speed.

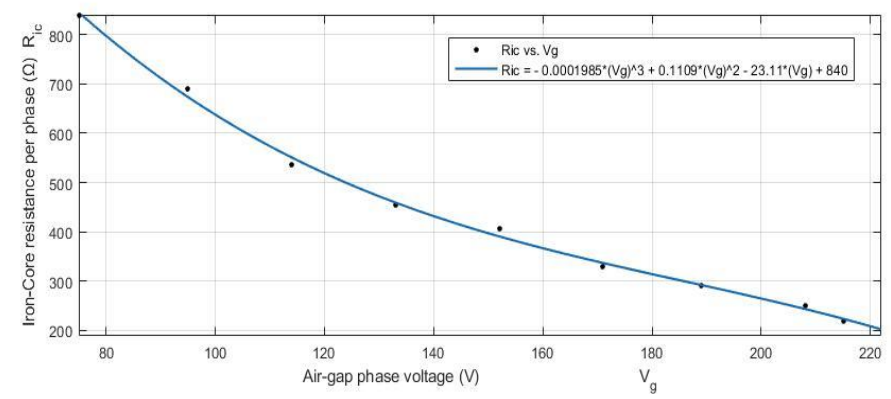

Fig. 5. Variation of iron core resistance with air-gap magnetizing voltage.

The magnetizing reactance per phase $X_{m}$ can be calculated as:

$$
X_{m}=V_{g}^{2} /\left(Q_{n \ell}-I_{o}^{2} \cdot X_{\ell s}\right)
$$

Figure (6) Shows the variation of magnetizing inductance $\left(L_{m}\right)$ with magnetizing current $\left(I_{m}\right)$ from the no-load test by rotating the machine at synchronous speed. 


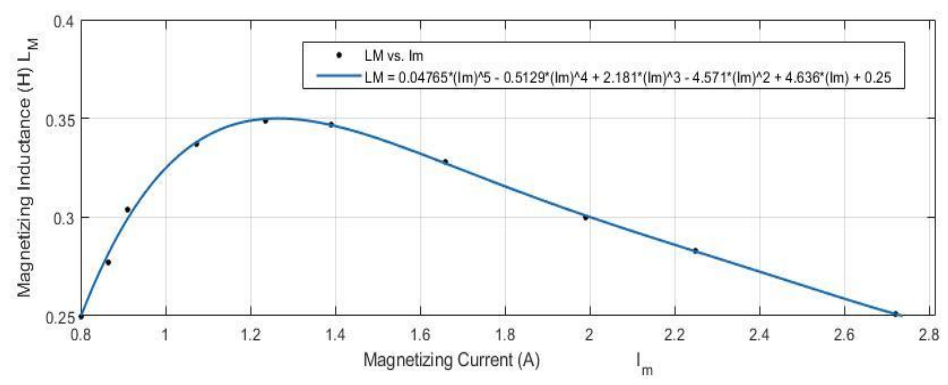

Fig. 6. Variation of magnetizing inductance with the magnetizing current.

The rotor iron core resistance per-phase $R_{\text {ric }}$ can be derived as a function of machine slip:

$$
R_{\text {ric }}=R_{\text {sic }} / s^{2}
$$

The total iron core resistance $\left(R_{i c}\right)$ can be obtained by adding $R_{\text {sic }}$ and $R_{\text {ric }}$ in parallel as:

$$
R_{i c}=R_{\text {sic }} /\left(1+S^{2}\right)
$$

The iron core resistance is a function of iron core temperature and the machine slip (s).

The stator stray loss resistance connected in series with stator circuit $\left(R_{S S S \ell}\right)$, as equivalent to the parallel $R_{s}$ and $R_{\text {sic }}$ with $X_{\ell s}$, can be derived as:

$$
R_{s S S \ell}=\left(X_{\ell S}\right)^{2} \cdot R_{S} /\left[R_{S}^{2}+X_{\ell S}^{2}\right]
$$

From equation (20), it can be shown that the stator stray load loss resistance depends mainly on the stator leakage flux and stator winding resistance, and the effect of stator iron core resistance can be neglected.

The rotor stray loss resistance connected in series with rotor circuit $\left(R_{r s s}\right)$, as equivalent to the parallel $R_{r}$ and $R_{r i c}$ with $\dot{X}_{\ell r}$, can be derived as:

$$
R_{r s s \ell}=s^{2} \cdot\left(\dot{X}_{\ell r}\right)^{2} / R_{r}
$$

From equation (21), it can be shown that the rotor stray load loss resistance depends mainly on the rotor leakage flux, rotor bar resistance, and rotor speed (machine slip).

The friction and windage loss resistance $\left(R_{f \omega}\right)$ can be determined from the no-load test as:

$$
R_{f \omega}=3 *\left[V_{g}-I_{r}\left\{\left(\dot{R}_{r}+R_{r s s \ell}\right)+j \dot{X}_{\ell r}\right\}\right]^{2} / P_{f \omega}
$$

Figure (7) shows the variation of $R_{f \omega}$ with air-gap voltage.

Where $P_{f \omega}$ is the friction and windage loss, which can be determined as:

$$
P_{f \omega}=P_{n \ell r}-P_{n \ell s}
$$

Where $P_{n \ell r}=$ the no-load power at rated speed; $P_{n \ell s}=$ the no-load power at synchronous speed. 


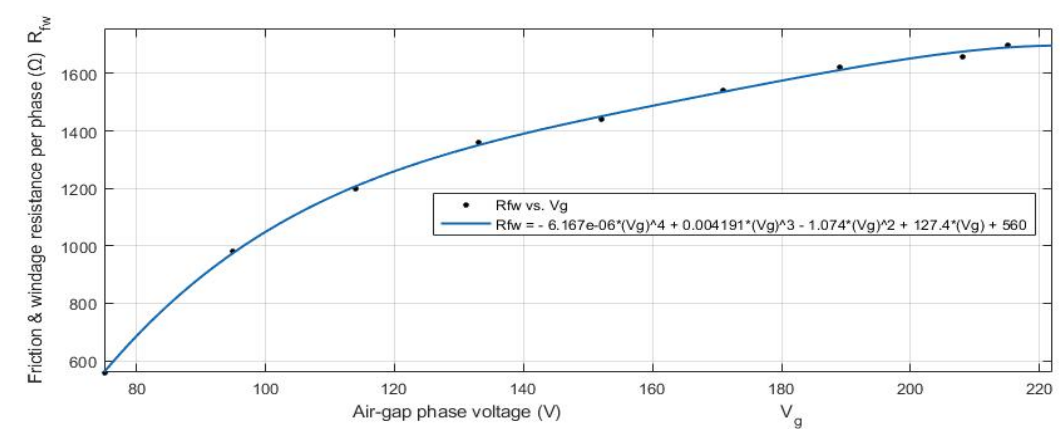

Fig. 7. Variation of friction and windage loss resistance with air-gap magnetizing voltage.

The factor $K_{T}$ in equation (16) represents the temperature coefficient of the iron core losses, and it represents the ratio of iron core losses at any temperature $(\mathrm{T})$ to that at reference temperature $\left(T_{o}\right)$, and can be determined by measuring the iron core loss and temperature at two points when the motor is loaded. This coefficient can be expressed as [9]:

$$
K_{T}=(1-D)
$$

Where $\mathrm{D}$ is the iron core power loss varying rate per ${ }^{\circ} \mathrm{C}$, and can be determined as:

$$
D=\frac{P_{i c\left(T_{o}\right)}-P_{i c(T)}}{P_{i c\left(T_{o}\right)}}
$$

\section{D- Correction factor for equivalent circuit parameters:}

i-) The skew-effect can be introduced to correct the rotor leakage reactance as:

The skew-rotor leakage reactance $X_{\ell r q}$ can be determined as [10]:

$$
X_{\ell r q}=X_{m} *\left(\frac{1}{K_{s q}^{2}}-1\right)
$$

Where $K_{s q}=$ the rotor-skew factor, given as [11]:

$$
K_{s q}=\sin \left(\pi \cdot P_{p} / Q_{r}\right) /\left(\pi \cdot P_{p} / Q_{r}\right)
$$

Where $P_{p}$ is the machine magnetic pole-pairs and $Q_{r}=$ the number of rotor bars. The total rotor leakage reactance can be calculated as:

$$
\stackrel{\prime}{X}_{\ell r(o)}=\frac{X_{m}}{K_{s q}^{2}}\left(1-K_{s q}^{2}\right)+\frac{\dot{X}_{\ell r}}{K_{s q}^{2}}
$$

The corrected rotor resistance due to the skew effect is obtained as:

$$
\dot{R}_{r(o)}=\dot{R}_{r} / K_{s q}^{2}
$$

ii-) skin-effect can be introduced to correct the stator resistance and leakage reactance as:

$$
R_{s(s)}=K_{s r} * R_{s(o)}
$$




$$
X_{\ell s(s)}=K_{s x} * X_{\ell s(o)}
$$

Where $K_{s r}$ and $K_{s x}$ are the skin-effect correction factors of stator parameters and can be given as [12]:

$$
\begin{gathered}
K_{s r}=\Delta *[\sinh (2 \Delta)+\sin (2 \Delta)] /[\cos h(2 \Delta)-\cos (2 \Delta)] \\
K_{s x}=(3 / 2 \Delta) *
\end{gathered}
$$

$[\sin h(2 \Delta)-\sin (2 \Delta)] /[\cos h(2 \Delta)-\cos (2 \Delta)]$

$$
\text { Where } \quad \Delta=D_{c u} * \sqrt{\pi \cdot f_{s} \cdot \mu_{o} \cdot \mathfrak{S}_{s}}
$$

Where $D_{c u}$ is the diameter of round copper conductor, $f_{s}$ is the supply frequency, $\mu_{o}$ is the magnetic permeability of copper material $\left(4 \pi^{*} 10^{-7} \mathrm{H} / \mathrm{m}\right)$ and $\mathfrak{S}_{S}$ is the electric conductivity of copper material $(1 /(\Omega . m)$ or Siemens).

iii-) skin-effect can be introduced to correct the rotor resistance and leakage reactance as [3]:

$$
\begin{aligned}
& \dot{R}_{r(s)}=\dot{R}_{r(o)} *\left[0.5+0.5 * \sqrt{S_{r} / S_{m}}\right] \\
& \dot{X}_{\ell r(s)}=\dot{X}_{\ell r(o)} *\left[0.4+0.6 * \sqrt{S_{m} / S_{r}}\right]
\end{aligned}
$$

Where $\left(S_{r}\right)$ is the rated machine slip and $S_{m}$ is the machine slip at maximum torque and can be calculated as [2]:

$$
S_{m}=\dot{R}_{r(o)} / \sqrt{R_{S(o)}^{2}+\left(X_{\ell S(o)}+\dot{X}_{\ell r(o)}\right)^{2}}
$$

iv-) stator and rotor resistances $R_{S(s)}$ and $\hat{R}_{r(s)}$ can be corrected to the temperature calculated at any load (measured load current) as [8]:

$$
\begin{gathered}
R_{S(T)}=R_{S(s)} * \frac{\left(T_{S}+K_{c}\right)}{\left(T_{o}+K_{c}\right)} \\
\dot{R}_{r(T)}=\dot{R}_{r(s)} * \frac{\left(T_{r}+K_{a}\right)}{\left(T_{o}+K_{a}\right)}
\end{gathered}
$$

where $T_{s}$ is the stator winding temperature at any load and can be calculated as:

$$
T_{S}=\frac{I_{S(\text { measured })}^{2}}{I_{S(\text { full load })}^{2}} *\left(T_{I}-T_{o}\right)+T_{o}
$$

$T_{r}$ is the rotor winding temperature at any load and can be calculated as :

$$
T_{r}=\frac{\left(I_{s(\text { measured })}-I_{n \ell}\right)^{2}}{\left(I_{s(\text { full load })}-I_{n \ell}\right)^{2}} *\left(T_{I}-T_{o}\right)+T_{o}
$$

Where $T_{I}$ is the temperature of insulation class design and equal to $75^{\circ} \mathrm{C}$ for class-A type. $T_{o}$ is the ambient temperature $\left(25^{\circ} \mathrm{C}\right) . K_{a}$ is a correction factor for aluminum material $\left(K_{a}=225\right)$, and $K_{c}$ is a correction factor for copper material $\left(K_{c}=234.5\right)$. 
Also, the corrected stator and rotor resistances $R_{S(T)}$ and $\hat{R}_{r(T)}$ can be calculated by another method as:

$$
\begin{aligned}
& R_{s(T)}=R_{s(s)} *\left[1+\propto_{c} *\left(T_{s}-T_{o}\right)\right] \\
& \hat{R}_{r(T)}=\hat{R}_{r(s)} *\left[1+\propto_{a} *\left(T_{r}-T_{o}\right)\right]
\end{aligned}
$$

Where $T_{s}$ and $T_{r} \quad=$ the calculated stator and rotor temperature at any load (equations (40) and (41)).

$\propto_{c}$ is the thermal temperature coefficient of copper material $\left(\propto_{c}=1 / 259.5\right)$, and $\propto_{a}$ is the thermal temperature coefficient of aluminum material $\left(\propto_{a}=1 / 250\right)$.

v-) motor rated slip $\left(S_{r}\right)$ can be corrected due to the temperature effect as [8]:

$$
S_{r(T)}=S_{r} * \frac{\left(T_{r}+K_{a}\right)}{\left(T_{I}+K_{a}\right)}
$$

The load resistance $\mathscr{R}_{r}(1-s) / s$ in the proposed equivalent circuit of the figure (3) can be derived as:

$$
\dot{R}_{r}(1-s) / s=1 /\left[1 /\left\{\frac{\hat{R}_{r}(1-s)}{s}-R_{r s s l}\right\}-1 / R_{f \omega}\right]
$$

\section{E- Including of magnetizing saturation in the equivalent circuit parameters:}

Most of the induction machines operate in a saturation region, and their magnetizing characteristics are non-linear in nature. The variation of magnetizing reactance $\left(X_{m}\right)$ is the main factor in generating the magnetizing voltage $\left(V_{g}\right)$, which is given as [13]:

$$
V_{g}=X_{m} \cdot I_{m}=\omega_{s} L_{m} I_{m}
$$

The magnetizing voltage is the main factor in generating the iron core losses, rotor current, mechanical losses, and output power. The magnetic saturation reduces the magnetizing reactance (or inductance) and this, in turn, reduces the magnetizing voltage and tends to increase the magnetizing current $\left(I_{m}\right)$, and hence, the losses will be increased, and the output power will be reduced. The saturation effect of the magnetizing inductance can be taken into account by using the relation of magnetizing reactance $\left(X_{m}\right)$ as a function of magnetizing current $\left(I_{m}\right)$, as:

$$
X_{m}=f\left(I_{m}\right)
$$

This function can be obtained experimentally from the no-load test at a variable supply voltage from $125 \%$ down to $25 \%$ of the rated value. The measurements of $X_{m}$ and $I_{m}$ can be interpolated by a curve fitting technique. Figure (6) shows the variation of saturated magnetizing inductance with the magnetizing current.

\section{F- Determination of moment of inertia for induction machines from retardation test:}

Where the motor rotates at no-load, the kinetic energy at the rotor shaft can be expressed as [14]: 


$$
E_{s h}=\frac{1}{2} J \cdot \omega_{m}^{2} \quad(\text { W.Sec. })
$$

Where $\mathrm{J}$ is the moment of inertia $\left(k_{g} \cdot m^{2}\right)$ and $\omega_{m}=$ the motor speed in mechanical radian per second. Also, at no-load, the rotor shaft power can be measured as:

$$
P_{s h}=P_{s c u}+P_{i c}+P_{f \omega}
$$

Where $P_{s c u}$ is the stator copper loss (W), $P_{i c}$ is the iron core loss (W) and $P_{f \omega}$ is the mechanical losses (W). Then:

$$
\begin{gathered}
P_{s h}=d E_{s h} / d t=\frac{J \cdot 4 \pi^{2} \cdot N_{r}}{3600} * \frac{d N_{r}}{d t} \\
\text { Or } J=P_{s h} /\left[\frac{4 \pi^{2}}{3600} * N_{r} * \frac{d N_{r}}{d t}\right]
\end{gathered}
$$

Where $N_{r} \quad=$ the motor speed in (r.p.m).

$d N_{r} / d t \quad=$ the derivative of rotor speed with respect to time and can be calculated from the retardation test of the motor (the slope of speed-time relation when the rate is retarded from noload to rest).

\section{G- Efficiency Determination from Parameters of Equivalent Circuit:}

The efficiency and performance characteristics of the induction motor can be determined from its equivalent circuit parameters of the figure (3). For a given the slip (s), the input impedance can be calculated as:

$$
\begin{gathered}
Z_{i n}=\left[R_{s}+R_{s s s \ell+j X_{\ell s}}\right]+\frac{Z_{m} \cdot \dot{Z}_{r}}{Z_{m}+\dot{Z}_{r}} \\
\text { Where } Z_{m}=\frac{R_{i c} \cdot X_{m}}{R_{i c}+X_{m}} \\
\dot{Z}_{r}=\left(\dot{R}_{r} / s\right)+j \dot{X}_{\ell r} \\
\text { Or } Z_{i n}=\frac{V_{p h}}{I_{p h}}
\end{gathered}
$$

The power factor angle $(\phi)$ is the same as the angle of $Z_{\text {in }}$, or the power factor can be calculated as:

$$
\begin{aligned}
\cos (\phi) & =\frac{R_{e q}}{Z_{i n}} \\
R_{e q} & =R_{s}+R_{s s s \ell}+\frac{\left(P_{a g}+P_{i c}\right)}{3 * I_{s}^{2}}
\end{aligned}
$$

Then, motor efficiency can be calculated as:

$$
\eta \%=\frac{P_{\text {in }} \text {-total losses }}{P_{\text {in }}} * 100
$$




$$
P_{\text {in }}=3 \cdot V_{p h} \cdot I_{s} \cdot \cos \phi
$$

Total losses $=\left(P_{s c u}+P_{s s s \ell}+P_{i c}+P_{r c u}+P_{r s s \ell}+P_{f \omega}\right)$, where the total losses can be calculated from equations (1) to (6).

\section{5- Results and Discussion}

The proposed equivalent circuit is simulated in a Matlab/Simulink Block-set for both motor and generator operation. Then the simulation results are compared with experimental results to show the validity of the proposed equivalent circuit model.

The test setup bench consists of an induction machine coupled with DC machine to determine the output load power of the induction machine when operates as a motor, and the DC machine is used as a prime-mover when the machine operates as a self-excited induction generator. The specifications and parameters of the DC machine and induction machine are given as:

DC machine: separately excited, $2.2 \mathrm{Kw}, 1500$ r.p.m , $V_{\text {field }}=220 \mathrm{~V}, I_{\text {field }}=0.8 \mathrm{~A}, I_{a}=$ $12 A, \mathrm{~J}=0.02 \mathrm{~kg}_{\mathrm{g}} \cdot \mathrm{m}^{2}$.

Induction machine: 3-phase, squirrel cage, $\Delta$-Connected, $220 \mathrm{~V}, 50 \mathrm{~Hz}$ with the following parameters:

$P_{\text {out }}=1500 \mathrm{~W}, I_{\ell}=6.6 \mathrm{~A}, \cos \phi=0.8, N_{s}=1500$ r.p.m, Pair-Poles $=2, R_{s}=5.1 \Omega$, $\hat{R}_{r}=3.5 \Omega, L_{\ell s}=0.016 \mathrm{H}, \hat{L}_{\ell r}=0.024 \mathrm{H}, L_{m}=0.28 \mathrm{H}, \mathrm{J}=0.03 \mathrm{~kg} \cdot \mathrm{m}^{2}, K_{T}=0.75$.

Figure (8) shows the theoretical and experimental results of machine terminal voltage variation with load current. Figure (9) shows the machine power factor variation with load current for simulation and experimental results. Figure (10) shows the theoretical and experimental results of machine output power variation with load current. Figure (11) shows the theoretical and experimental results of machine efficiency variation with load current. From these results, it can be concluded that the proposed equivalent circuit gives high accuracy for machine performance calculation, except at high load current, there is a small difference between the experimental and theoretical results due to the saturation in cross-coupling magnetizing inductance and the saturation in leakage inductances are not considered in this model.

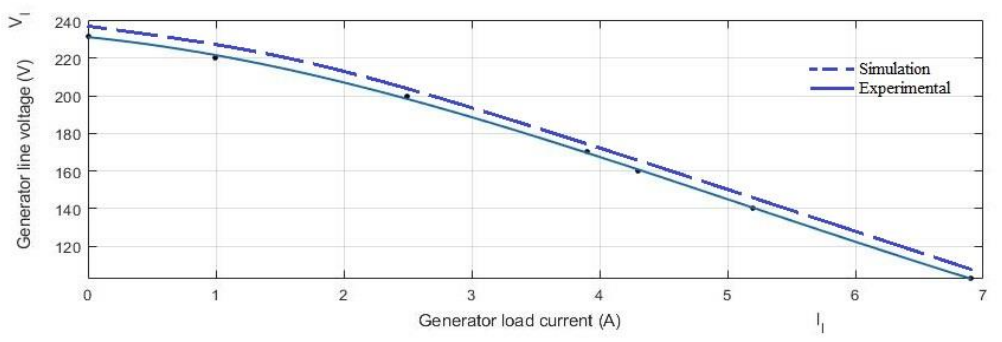

Fig. 8. Variation of machine terminal voltage with load current. 


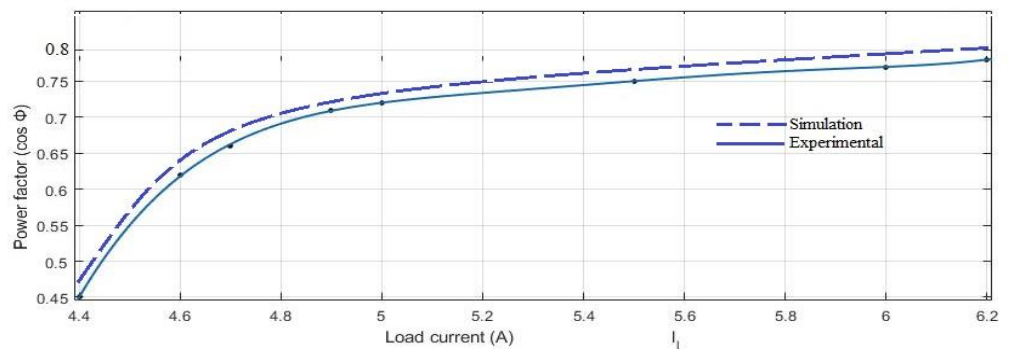

Fig. 9. Variation of power factor with load current

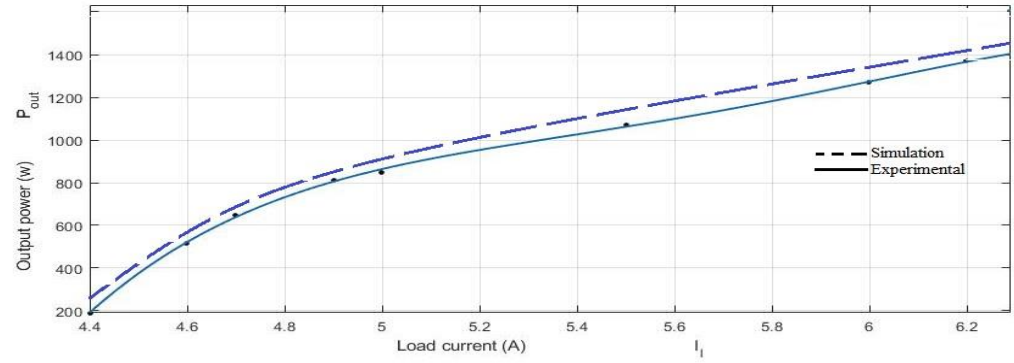

Fig. 10. Variation of machine output power with load current

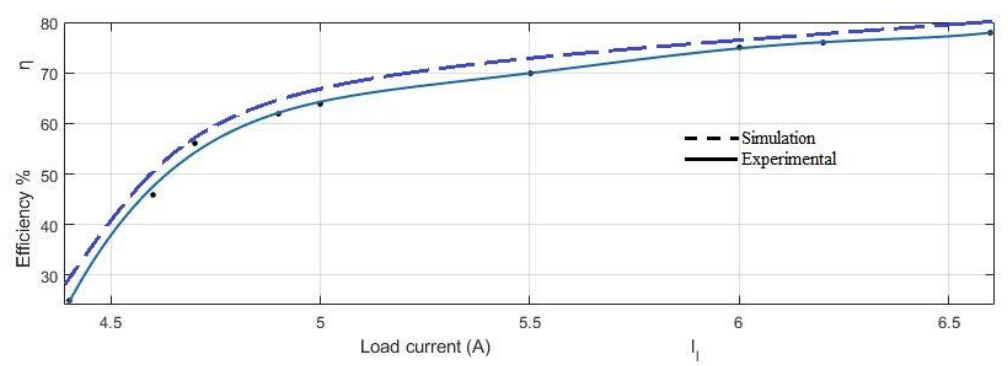

Fig. 11. Variation of machine efficiency with load current.

\section{6- Conclusion}

Complete equivalent circuit parameters are proposed in this paper for accurate determination of machine performance at different operating conditions, considering the effect of iron core loss, stray load loss, skin effect, temperature effect, skew effect and friction and windage losses. Besides of these considering parameters effect, the method of equivalent circuit components determination requires only the conventional measurements on the induction machine, such as no-load, load, and blocked rotor test. Both stator and rotor iron core resistance depend on the air-gap magnetizing voltage and due to the air-gap voltage depend mainly on the circuit frequency, the rotor frequency is minimal when compared with stator frequency and this leads to a very high rotor iron core resistance and this resistance can be neglected without losing the accuracy of calculation of machine performance. Both stator and rotor stray load loss depend on the square of circuit frequency. The rotor stray load loss resistance can be eliminated from 
the proposed equivalent circuit without losing the accuracy of the performance calculation of the machine. The stator stray loss depends highly on the stator winding resistance as well as stator frequency, and this resistance depends on the cross-sectional area of the windings, and for this reason, the percentage of stray load loss in large machines is small when compared with that of small size machine.

\section{References}

[1] X. Zhan, G. Zeng, J. Liu, Q. Wang and S. Qu, " A review parameters identification methods for asynchronous motor", International Journal of Advanced Computer Science and Applications, Vol. 6, No. 1, pp. 104-109, 2015.

[2] J.M.C. Guimaraes, J.V. Bernardes, A.E. Hermeto and E.C. Bortoni, " Parameter determination of asynchronous machines from manufacturer data sheet ", IEEE Transactions on Energy Conversion, Vol. 29, No. 3, pp. 689-697, September 2014.

[3] M.H. Haque," Determination of NEMA design induction motor parameters from manufacturer data", IEEE Transactions on Energy Conversion, Vol. 23, No. 4, pp. 997 1004, 2008.

[4] C.H. Ozyurt," Parameter and speed of induction motors from manufacturer's data and measurements", Master Thesis, The Graduate School of Natural and Applied Science, The Middle East Technical University, Ankara, Turkey, 2005.

[5] D. Lindenmeyer, H.W. Dommel, A. Moshref and P. Kundur," An induction motor parameter estimation method", Electrical Power and Energy System, Vol. 23, No. 4, pp. 251-262, 2001.

[6] J. Pedra and F. Corcoles, "Estimation of induction motor double-cage model parameters from manufacturer data", IEEE Transactions on Energy Conversion, Vol. 19, No. 2, pp. 310-317, 2004.

[7] S.A. Al-Jufout, W.H. Al-Rousan, and C. Wang," Optimization of induction motor equivalent circuit parameters estimation based on manufacturer data", Journal of Energies, Vol. 11, 1792, pp. 1-13, July 2018.

[8] IEEE Power Engineering Society," IEEE Standard test procedure for polyphase induction motors and generators", ANSI, IEEE Standard 112-B, November 2004.

[9] S. Xue, W.Q. Chu, Z.Q. Zhu, J. Peng, S. Guo, and J. Feng," Iron loss calculation considering temperature influence in non-oriented steel laminations ", The Institute of Engineering and Technology, Science Measurement and Technology, Vol. 10, No. 8, pp. 846-854, November 2016.

[10] S.C. Engebretson," Induction machine stray loss from inter-bar current", Doctoral Thesis, Massachusetts Institute of Technology, September 2009.

[11] G. Joksimovic," Dynamic model of cage induction motor with the number of rotor bars as parameter", The Journal of Engineering, Vol. 2017, No. 6, pp. 205-211, 2017.

[12] I. Boldea and S.A Nasar, " The induction machines design handbook", CRC Press, Taylor and Francis Group, Second Edition, 2010.

[13] M. Ranta, " Dynamic induction machine models including magnetic saturation and iron losses", Doctoral Dissertation, Aalto University Publication Series, 171, 2013.

[14] R. Babau and I. Boldea," Complete parameter identification of large induction machines from no-load acceleration-deceleration tests", IEEE Transactions on Industrial Electronics, Vol. 54, No. 4, pp. 1962-1971, August 2007. 